\title{
Fortifying Bakso (Restructured meat product) with potential encapsulated functional strategies - a mini review
}

\author{
*Rahardiyan, D. \\ Faculty of Agricultural, Catholic University of De La Salle - Manado, Kombos, Kairagi I, Manado - North \\ Sulawesi 95253
}

Article history:

Received: 5 June 2020

Received in revised form: 15 July 2020

Accepted: 29 July 2020

Available Online: 29

October 2020

\section{Keywords:}

Meatballs,

Bakso,

Fortification,

Encapsulation,

Functional food

DOI:

https://doi.org/10.26656/fr.2017.5(1).277

\begin{abstract}
This review revisits the Indonesian Bakso, a restructured meat product that is well preferred by wide ranges of social economy classes of the Indonesian community. Bakso has been a very good low-cost protein source for all. By understanding the complexity of the colloidal structure of Bakso that is constructed by the protein matrix and swelling starch granule interactions, it is also made clear in this review that Bakso has the potential for being more than just a low-cost protein source meal enjoyed by all. The colloidal complexities of the food system in Bakso allows it to entrap fortifications of bioactive compounds, bringing Bakso to the realm of functional foods. Various simple attempts have been made to improve the eating quality of Bakso by simple substitution of the starch with other plant-sourced starches that have functional properties. Effectiveness of these attempts had not scratched the surface of elevating Bakso into the functional food world, therefore it is an opened option to explore the potential of bringing encapsulation of functional components in this mini review processes into the mix. The variables in terms of bioactive functions, sources, polarities, solubilities and reactivities of the various compounds and encapsulating materials is still a large opportunity for further exploration. With encapsulation in play, this opens the doors of refitting Bakso with more varieties of bioactive compounds, and the elements of modifications that can be made to elevating Bakso in the functional food world.
\end{abstract}

\section{Introduction}

The consumption of animal meat for a source of food, especially protein, has been a tradition in the diet of mankind for as long as anyone can tell (Baugreet et al., 2018). The consumption of meat does not only provide a source of protein, but also a number of quality nutrients such as vitamin and minerals. Unfortunately, meat consumption, especially red meat has its consequences in regard to coronary heart diseases mainly caused by saturated fatty acids (Mireles Arriaga et al., 2017). Therefore, various techniques, namely meat restructuring, has been applied in modifying meat to incorporate health functions (functional components) from other sources, like plants (Arriaga et al., 2017) and also other protein sources (Baugreet et al., 2018). Meat restructuring is a process that involves in disenewing and particle size reduction (chopping, cutting, sectioning, tenderization, flaking, grounding) and further reforming the emulsions in the forms of restructured steak, patties, and other forms of reformed meat batter such as sausages and meatballs, which is then finalized by thermal setting or setting by heat (Anandh and Villi, 2018). Restructured meat products can be made from comminuted meat to a fine emulsion and well combined with starch, fat and various herbs and spices to refine the taste. As with most Asian countries, in particular, South East Asia, the comminuted meat products as meatballs are very popular and widely consumed (Tee and Siow, 2017). Meatballs in Indonesia are prepared from a smooth textured emulsion of meat, tapioca starch, garlic, salt and pepper, before spooning and shaping to a ball and finally boiled to cook, and when the protein matrices set thus entrapping the swelling starch with all the flavors. Indonesian meatballs (Bakso) is a very popular streetfood and is comfort-food to various levels of social classes in Indonesian society. Prices vary easily depending on the concentration of starch versus meat in the composition of the emulsion mixtures, thus Bakso, depending on the source of meat used and concentrations of starch in the mixtures may very well become a very enjoyable low-cost protein source for all class levels of the society. 
As with other restructured meat (comminuted meat products), bakso, also during cooking (heating) experiences a setting of protein matrices from the denaturation and coagulation of the matrices, while entrapping the swelling gelating starch with flavor compounds from the garlic, also the flavors from the seasonings (salt and pepper). With a protein content of $13.38-14.44 \%$, and widely found in a widespread of marketplaces in cities and villages throughout Indonesia with a range of prices, bakso is absolutely noted as Indonesia's ethnic food that is categorized as low-cost protein source for all social-economic classes of the Indonesian societies (Suniati and Purnomo, 2019). Furthermore, with the capacity of the swelling tapioca gelation and the setting of the protein matrices, the food colloid system of bakso is also a perfect vessel to entrap many functional components that may be incorporated to fortify the product, and thus the perfect vessel for bringing nutrients of various dietary fulfilment and wellness to the community, such that has been studied by many (Kartikawati and Purnomo, 2018; Suniati and Purnomo, 2019). Gelling properties entrapping functional components work perfectly to insulate the functional components (bioactive compounds) from the heat process that these products will go through during the cooking process. Encapsulation of functional components (bioactive compounds) would add an extra layer of protective insulation from heat, hence will reduce loss or formations of unpleasant flavors or odors due to oxidation of the bioactive compounds; and also provide a more controlled delivery system of the compound, making the bioactive compounds more effective in delivering their health functions. This review is aimed to take a closer look into the idea of fortifying bakso by taking advantage of its unique formation of protein matrices and starch swelling properties, and further upgrading these possibilities with encapsulated bioactive compounds in which bakso as a popular food to the people may then have the potential as a means of delivery for health benefitting compounds.

\section{Protein matrices of restructured meat and bakso matrices}

Restructured meat proteins are closely related to the manipulation of muscle proteins to forming a threedimension gel matrix that emulsifies fats and water, also other dissolved functional components both naturally occurring or fortified. Therefore, restructured meat products or known as muscle food are heterogeneously complex food systems of the myofibrillar proteins itself and its internal construct and interactions, also involving non-muscle material that has been incorporated into the ingredients such as starch and various spice (Xiong and
Kenney, 1999). In which the interactions of actin and myosin and proteolysis of the myofibrillar proteins are of the most contributing proteins in muscle food texture and gel matrix structure (Li et al., 2012).

Before any attempts in actin-myosin structures manipulations within the restructured meat matrix, a good sneak peeks to the origin of the actin-myosin structure during live muscle contraction would be beneficial. Various cell movement in the muscle is driven by the actin-myosin network contractility in the cytoskeletal structures (Williams and Holt, 2018; Wollrab et al., 2019). Muscle contraction mechanisms are determined by the positions of the actin-myosin filaments that are arranged in a bipolar repeating array, entrapped within the antiparallel actin filaments (Wollrab et al., 2019). Activated myosin filament head ends that are bound to actin in the cross-bridge network then undergoes a structural alteration that would generate sliding forces and kinetically moves the protein passing each other, thus the contraction occurs. The rigor matrices of this myofibrillar protein configuration are constructed by a complex interaction of the actin and myosin resulting in a structure named actomyosin (HuffLonergan and Lonergan, 2005). The importance of this knowledge involves in which state of the meat/the muscle is; contracted or not (relaxed); as well as the rigor -mortis status of the muscle in which before the reconstitution or restructuring process of the matrix network would take place. This then correlates to the tenderness and texture of the meat and its final product. Throughout the rigor-mortis process, meat toughness will build up through the early stages of the process and would eventually lose structural integrity along time as specific myofibrillar degradation and fragmentation occur as a result of proteolysis ( $\mathrm{Li}$ et al., 2012). Therefore, modifications to this matrix and its complex interactions within the protein constructs and the modification techniques employed plays an important role in the functional properties of the system as such in the properties of solubility, viscosity, elasticity, formations of emulsions and gel forms (Guadalupe Rodríguez et al., 2017).

Traditionally, Indonesian Bakso is meatballs that are produced from pre-rigor meat or the early stages of rigor -mortis which is collected from traditional butchers and traditional wet markets (Purnomo and Rahardiyan, 2008). Myofibrillar proteins of pre-rigor meat at the early rigor-mortis process would retain a certain toughness and textural properties that in the case of Bakso is more preferred by the consumers (Rahardiyan and Mcmillin, 2004). Many research have noted substantially that changes in actin-myosin interactions 
have potential effects on tenderization process where actomyosin structures of aged meat had weaker bonds compared to pre-rigor or early rigor-mortis meat (Li et al., 2012). Whereas in Bakso made of early post mortem (rigor-mortis) meat had tougher texture due to the improved emulsifying capacity with more free myosin that promotes better gelling properties, while other myofibrillar proteins that perform in the matrices structural rigidity (actin) would regulate the viscoelasticity-ness of the structure (Purnomo and Rahardiyan, 2008). Myosin and actomyosin myofibrillar protein structures in Bakso appears as a thin thread of protein strand interconnecting between each other forming a coherent web-like net matrix structure that would entrap the densely swelled tapioca granules and thus contributes the unique texture of the bakso meatballs (Rahardiyan and Mcmillin, 2004).

\section{Starch gelatination in bakso}

A major non-meat ingredient that is added to the raw batter of restructured meat products such as bakso and other meatballs are starches (Muthia et al., 2010; Prabpree and Pongsawatmanit, 2011). Amongst the rheological properties of starch, the most important characteristics to the structural construction of the food systems in various processing conditions are swelling, gelling and retro degradation (Tee and Siow, 2017). The main functions of starches in restructured meat are mainly as binders in regard to fat binding and water holding capacity, but their natural rheological properties under heat processing and various freeze-thaw conditions have many contributions to the desired textural properties of the end product (Totosaus, 2009; Tee and Siow, 2017). The addition of starch fillers in restructured meat products also has an economical advantage reducing formulation cost by the means of reducing cooking loss and increasing yields (Totosaus, 2009). Starches utilized in restructured meat products are commonly in ranges of $3 \%$ to $12 \%$ and includes wheat, corn, potato and tapioca and various modifications of these starches (Tee and Siow, 2017).

Bakso, is prepared with the addition of starch from cassava (tapioca) as the main starch filler in the raw batter (Kartikawati and Purnomo, 2018). Tapioca addition in bakso vary in concentration of the total batter, depending on the rigor condition of the meat and the desired texture of the final product, but most are in the ranges of $5-15 \%$ (Rahardiyan and Mcmillin, 2004; Purnomo and Rahardiyan, 2008). The swelling and gelatinization properties of starch granules in bakso were reported to appear in dense spherical aggregates (Purnomo and Rahardiyan, 2008). Its functional properties were noted to have a large contribution to emulsion stability, elasticity and the prevention of water loss due to syneresis in frozen-thaw cycles (Rahardiyan and Mcmillin, 2004). In other test subjects as in fish balls, starch properties demonstrated similar performances in bakso, where even up to the 6th freezethaw cycle gell strength, drip loss and fish ball color showed insignificant changes $(p \geq 0.05)$ (Tee and Siow, 2017). Meanwhile, in fish sausages at $p \geq 0.05$, increasing concentrations of tapioca starch up to $14 \%$ also improved the textural qualities and freeze-thaw stability (Prabpree and Pongsawatmanit, 2011).

In the event of heat processing, when the temperature reaches $60^{\circ} \mathrm{C}-70^{\circ} \mathrm{C}$, starch granules will irreversibly swell to several times their original particle size. At the same time, the myofibrillar proteins sets, and the swelling starch granules fill the spaces between the setting network of matrices. These dense swollen aggregates that fill the in-betweens of the myofibrillar matrices creates an insulating material entrapping and protecting the flavours and spices that are added to the mix. Gelation and swellings of the starch granules would be perfect in entrapping and protecting not just heat sensitive flavour compounds, but also for insulating bioactive components in the event of fortification. Thus, making restructured meat products (like bakso) the perfect delivery medium to carry functional components, especially in Indonesia where the popularity of bakso is widespread ranges of ages and social classes of the population. Many efforts have been made in fortifying bakso in terms of making bakso functional food and promoting various health benefits through bakso.

\section{Encapsulated of functional fortifications embedded in matrices and gelation}

Functional food, is food that is fortified, enhanced or enriched with certain bioactive functional, nutraceutical or food components and therefore considered to be healthy or providing the consumers a benefit in health that is beyond the provided daily nutrition (Bratovcic and Suljagic, 2019). Functional food and food bioactive components have been growing into a huge and promising aspect of the Food Industry (de Vos et al., 2010). More and more bioactive, nutraceuticals and various functional components have recently been identified and proven to have a positive impact to the human health and wellness, but many are prone to rapid inactivation and rapid degradation during processing or digestion. Therefore, methods of delivery that may protect these components, that their full potential may be harnessed before any inactivation or degradation is experienced is an important task. Thus, is where the important role of encapsulation is introduced (AlpizarVargas et al., 2019). 
Encapsulation is a good delivery system to achieve stable transport and good control of the diffusion of the active compounds into the metabolic system (de Vos et al., 2010). Encapsulation is a process that entraps a certain compound or substance in another compound and therefore renders a final complex particle somewhere in between a few nanometers to a few millimeters, where the substance encapsulating will be the carrier, coating or external phase that protects the more sensitive inner material that will be the bioactive component being delivered (Bratovcic and Suljagic, 2019). Microencapsulation or nanoencapsulation is considered accomplished when the active component to be coated (the more known as the active core; usually in gas or liquid phase) is completely coated by a solid phase secondary material that then will form a capsule surrounding the previously mentioned active core, in which the complex end particle when ranging from 1$1000 \mu \mathrm{m}$ is then considered microencapsulation while sized within submicron range would then be considered nano-encapsulation (Alpizar-Vargas et al., 2019; Bratovcic and Suljagic, 2019). Determining the best wall material (secondary phase) and the determination of the encapsulation technique in regards with polarity, solubility and reactivity in the function as a wall matrix emulsion structure are the most important elements of the encapsulation process (Mehrad et al., 2015). Microencapsulation processes are commonly executed in a physical colloidal emulsion manner using water and oil. This form factor is usually seen in a water-oil-water (WOW) configuration. In which the oil droplet will be dispersed in an outer layer of the aqueous phase, and the bioactive compound would be encapsulated within the inner phase after drying. Performing an encasement in the nano-scaling, on the other hand, is conducting a layering process with nanofilms (polymers of nanometers in size) using nanocomposites, nanoemulsification and nano-structuration techniques. Many techniques in nanoencapsulation have been explored including spray-drying, freeze-drying, nanoprecipitation, liposome preparation and supercritical fluid, but these techniques though known for in industries are also not too favored due to the extreme heat treatments involved in the process would affect the efficiency of the process and stability of the compound (Wen et al., 2017). These techniques would employ carbohydrates, proteins or lipids as the nanocarriers (Bratovcic and Suljagic, 2019). Ion gelation technique is amongst one of the techniques that result in a stable nanoparticle and is simple and organic solvent-free. This technique utilizes the interaction of positively charged polymer like chitosan $(\mathrm{Ch})$ and polyanions (Trisodium Polyphosphate, TPP) (Bratovcic and Suljagic, 2019). Nanoencapsulation by means of electrospinning is also a technique mostly used. Electrospinning is an electrohydrodynamic process that works by spinning the bioactive compounds within fiber that is electrospun producing a sub-micron or nano-polymer fiber. This technique is relatively new but also gaining popularity in the industry due to their advantages as their relatively easy to use, not involving thermal process and costeffective method (Wen et al., 2017; Raval and Ramani, 2019). The prospects of electrospinning as a method nanoencapsulation is gaining to be a future trend due to the fact the process is done in room temperature (Raval and Ramani, 2019).

The food colloid system of the restructured meat emulsion is a perfect matrix to entrap bioactive functional components, provided that some sensitive bioactive may need to be encapsulated to protect them from inactivity, oxidation or degradation due the extremities of the processing. Thus, would be the role of the swelling starch granules within the bakso matrix, that would function as the perfect insulator and also an anchor for the wall material capsule biopolymers. Even though micro/nano-encapsulation is emerging as an effective delivery system of bioactive compounds, with all the current wall materials and the most recent developments of encapsulation methods and techniques it is still a very expensive process and incorporating these processes to any products in the street-food peddler level would still need further feasibility study. When the product, like bakso, is produced in an immense industrial scale and fortified with encapsulated bioactive compounds the likelihood of incorporating these new trends in encapsulation might still appear to have an economical advantage.

\section{Potential of encapsulated functional components embedded in bakso matrices}

Providing encapsulation process may protect the functional components from various external extremities (such as heat) that would ruin the functionality of the functional components, the food colloidal matrix of restructured meat would add the extra cushion of security for the functional component added. Especially in meatballs like bakso, wherein bakso the aggregates of swollen starch granules are dense enough entrapments for keeping the encapsulated fortification materials safe along with other spice components (Rahardiyan and Mcmillin, 2004). Many efforts in fortifying bakso have been carried out throughout the years. This is due to the fact that bakso is a very popular street food amongst south-east Asian communities, including Indonesia (Purnomo and Rahardiyan, 2008). Therefore, it has become the perfect vessel for various nutrient intake programs. From the basic requirements of protein intake 
to the fortifications of functional nutrients, all have been executed with bakso as the choice of food for the carrying vessel.

Substituting starch components (tapioca) with other starch sources that have functional elements in them would be the simplest method of fortifying bakso. A research was conducted to substitute the starch of bakso with Goroho Banana flour (Musa acuminafe). This particular banana, endemic to North Sulawesi that is considered to have the potential to have positive impacts on diabetes type $2 \mathrm{~m}$. Results of the study indicated that organoleptically substitution of tapioca flour to Goroho flour up to $5 \%$ was most desired, although at $10 \%$ Goroho flour had the highest DPPH value at $27.95 \pm 0.88 \%$ (Suniati and Purnomo, 2019). Another simple substitution process to bring functional elements to bakso was also studied by substituting the tapioca starch with rice bran. This study was carried out by comparing 3 varieties of rice bran that was substituted to bakso tapioca flour and was tested on their antioxidant activities as well as organoleptic acceptances. The best substitution based on organoleptically was $50 \%$ Serang rice bran, meanwhile, the antioxidant activities of this rice bran were in a good range of $16.75 \%$ to $35.78 \%$ at a $\mathrm{p}<0.05$ with a total phenolics of $37.82-90.81 \mathrm{mg} / 100 \mathrm{~g}$ and thus, it was concluded bakso eating quality had improved (Kartikawati dan Purnomo, 2018). Substitution of tapioca in bakso formulation has been quite the trend in improving bakso as a media for better community eating.

A study on substituting the tapioca starch to Moringa oleifera leaves was also conducted to see if Milkfish bakso (Milkfish Meatballs) may improve in eating quality with extended health benefits. In this work, a $10 \%$ addition of the Moringa oleifera leaves was the preferred composition with added gelling agent to maintain the texture and structure (Minantyo et al., 2019). The gelling agent added was required for keeping up the structure since Moringa oleifera leaves were significantly low on starch and gelling power. Hence, with encapsulation of functional components such as Moringa oleifera extracts can be added without lessening the concentration of tapioca starch and thus the gelling power of the colloid system would be retained, while theoretically the extracts would be well protected from the extremities of processing and hurdles of preservation processes. Encapsulation would also serve to protect the unstable and vulnerable functional components and bioactive compounds from the presence of oxygen or undesired light penetration in the product (Wen et al., 2017). If such is so, then the food colloid matrices of bakso would be better potential for carrying various other extracts, functional components and other beneficial phytochemicals such as phenols, flavonoids, antioxidants and vitamins from various plant materials like the Mimosa pudica (Altemimi et al., 2017; Rahardiyan et al., 2019) or tea (Camelia sinensis) catechins (Rahardiyan, 2018); or even particular oilsoluble extracts of the tocopherol - tocotrienol containing red variety rice brans (Moko et al., 2019). By adding encapsulated natural antimicrobial agents, such as the tea catechins that in its nature to have the capacity to inhibit various food borne pathogens and other contaminating microbial source of spoilages (Rahardiyan, 2018), it is safe to presume that to a certain amount the additions of chemical preservatives commonly used in mass-produced bakso can also be limited, thus would improve not only the eating quality but also eating safety of bakso especially in the mass production (industrialization) level.

\section{Conclusion}

Bakso is a restructured meat product that is shaped into balls (meatballs) that is very common in Asian communities, even in Indonesia. Bakso has a unique set of food colloidal system that is very complex, consisting of a set of meat protein matrices, in which the during the forming process of this protein matrices entraps along with with-it gelatinizing starch granules from the added tapioca starch in the batter. Along with this process, within the food system of Bakso is also trapped various flavor compounds from the added ingredients. Due to this uniques matrix construct of Bakso colloidal system, Bakso is very potential to be improved in both the functional - nutritional aspects and in the food microbial safety aspects, since this entrapment process would become great insulation for various functional components and fortified nutrients from other natural plant source materials. Many attempts at improving the eating and health quality of Bakso has been made from the simplest methods adding flour substitutions with starch-based plants that also has strong functional properties. Never an attempt has been made in fortifying Bakso with encapsulated plant-based functional components. This would be an area yet to be explored. Disregarding the costs incurred for the extraction process of the plant functional components and the encapsulation process alone, encapsulation of extracted plant-based functional bioactive compounds would be a good method of delivery by trapping these encapsulates within the Bakso matrix. Therefore, even oil/lipid soluble bioactive compounds would be able to be fortified in the Bakso matrix. Hence it is necessary to explore more economical wall materials (secondary phase) with variations on polarity, solubility and reactivity and a more economical technique in encapsulating bioactive compounds to ensure better delivery. 


\section{References}

Alpizar-Vargas, L., Zúñiga-Montero, C., RodríguezMurillo, A., Vargas-Vásquez, A. and Vega-Baudrit, J. (2019). Nutraceuticals: definition, applied nanoengineering in their production and applications. International Journal of Biosensors and Bioelectronics, 5(3), 56-61. https:// doi.org/10.15406/ijbsbe.2019.05.00154

Altemimi, A., Lakhssassi, N., Baharlouei, A., Watson, D. and Lightfoot, D. (2017). Phytochemicals: Extraction, Isolation, and Identification of Bioactive Compounds from Plant Extracts. Plants, 6(4), 42. https://doi.org/10.5912/jcb722

Anandh, M. and Villi, R. (2018). Effect of Spent Hen Meat Emulsion and Ground Meat on Quality and Acceptability of Chicken Meat Cutlets. International Journal of Livestock Research, 8, 33-40. https:// doi.org/10.5455/ijlr.20180506044907

Baugreet, S., Kerry, J.P., Allen, P., Gallagher, E. and Hamill, R.M. (2018). Physicochemical characteristics of protein-enriched restructured beef steaks with phosphates, transglutaminase, and elasticised package forming. Journal of Food Quality, 2018. https://doi.org/10.1155/2018/4737602

Bratovcic, A. and Suljagic, J. (2019). Micro- and nanoencapsulation in food industry. Croatian Journal of Food Science and Technology, 11(1), 113-121. https://doi.org/10.17508/cjfst.2019.11.1.17

de Vos, P., Faas, M.M., Spasojevic, M. and Sikkema, J. (2010). Encapsulation for preservation of functionality and targeted delivery of bioactive food components. International Dairy Journal, 20(4), 292 -302. https://doi.org/10.1016/j.idairyj.2009.11.008

Guadalupe Rodríguez, C., José Ramírez de, L., Guadalupe Bustos, V. and Octelina Castillo, R. (2017). Properties of fish and beef restructured by MTG derived from Streptomyces mobaraensis grown in media based on enzymatic hydrolysates of sorghum. Czech Journal of Food Sciences, 35(6), 517-521. https://doi.org/10.17221/422/2016-cjfs

Huff-Lonergan, E. and Lonergan, S.M. (2005). Mechanisms of water-holding capacity of meat: The role of postmortem biochemical and structural changes. Meat Science, 71(1), 194-204. https:// doi.org/10.1016/j.meatsci.2005.04.022

Kartikawati, M. and Purnomo, H. (2018). Improving meatball quality using different varieties of rice bran as natural antioxidant. Food Research, 3(1), 79-85. https://doi.org/10.26656/fr.2017.3(1).220

Li, S., Xu, X. and Zhou, G. (2012). The roles of the actin -myosin interaction and proteolysis in tenderization during the aging of chicken muscle. Poultry Science,
91(1), 150-160. https://doi.org/10.3382/ps.201101484

Mehrad, B., Shabanpour, B., Jafari, S.M. and Pourashouri, P. (2015). Characterization of dried fish oil from menhaden encapsulated by spray drying. AACL Bioflux, 8(1), 57-69.

Minantyo, Winarno, H. and Kartikawati, P.S. (2019). The improvement of nutrition quality and organoleptic characteristics of Indonesian milkfish meatball by adding kelor (Moringa oleifera Lam) leaves. International Food Research Journal, 26(1), 263-268.

Mireles Arriaga, A.I., Ruiz-Nieto, J.E., Juárez Abraham, M.R., Mendoza Carrillo, M., Hernández Ruiz, J. and Sanzón Gómez, D. (2017). Functional Restructured Meat: Applications of Ingredients Derived From Plants. Revista Vitae, 24(3), 196-204. https:// doi.org/10.17533/udea.vitae.v24n3a05

Moko, E. M., Ngangi, J. and Rahardiyan, D. (2019). Oxidative stability of crude extract of red variety rice bran from Minahasa, north Sulawesi on lipid-based food products. Food Research, 3(3), 249-257. https://doi.org/10.26656/fr.2017.3(3).236

Muthia, D., Nurul, H. and Noryati, I. (2010). The effects of tapioca, wheat, sago and potato flours on the physicochemical and sensory properties of duck sausage. International Food Research Journal, 17 (4), 877-884.

Prabpree, R. and Pongsawatmanit, R. (2011). Effect of tapioca starch concentration on quality and freezethaw stability of fish sausage. Kasetsart Journal Natural Science, 45(2), 314-324.

Purnomo, H. and Rahardiyan, D. (2008). Indonesian traditional meatball. International Food Research Journal, 15(2), 101-108.

Rahardiyan, D., Poluakan, M., Moko, E.M. and Ngangi, J. (2019). The fractions of phenolic and flavonoid compounds of the leaves of north Sulawesi's bashful plant (mimosa pudica linn). Journal of Physics: Conference Series, 1317, 012066. https:// doi.org/10.1088/1742-6596/1317/1/012066

Rahardiyan, D. and Mcmillin, K.W. (2004). Indonesian bakso meatball properties with postmortem meat time and tapioca starch concentrations presented at the $50^{\text {th }}$ International Congress of Meat Science and Technology. Helsinki, Finland.

Rahardiyan, D. (2018). Antibacterial potential of catechin of tea (Camellia sinensis) and its applications. Food Research, 3(1), 1-6. https:// doi.org/10.26656/fr.2017.3(1).097

Raval, D. and Ramani, V. (2019). A Review on Electrospinning Technique and Its Application in the 
Field of Nanoencapsulation of Bioactive

Compounds. International Journal of Current Microbiology and Applied Sciences, 8(7), 2724 2730. https://doi.org/10.20546/ijcmas.2019.807.334

Suniati, F.R.T. and Purnomo, H. (2019). Goroho (Musa acuminafe, sp) banana flour as natural antioxidant source in Indonesian meatball production. Food Research, 3(6), 678-683. https://doi.org/10.26656/ fr.2017.3(6).302

Tee, E.T. and Siow, L.F. (2017). Effect of tapioca and potato starch on the physical properties of frozen spanish mackerel (Scomberomoru guttatus) fish balls. International Food Research Journal, 24(1), 182-190.

Totosaus, A. (2009). The use of potato starch in meat products. Food, 3(1), 102-108. Retrieved from http://www.globalsciencebooks.info/ JournalsSup/09FOOD_3_SI1.html

Wen, P., Zong, M.H., Linhardt, R.J., Feng, K. and Wu, H. (2017). Electrospinning: A novel nanoencapsulation approach for bioactive compounds. Trends in Food Science and Technology, 70, 56-68. https://doi.org/10.1016/j.tifs.2017.10.009

Williams, C.D. and Holt, N.C. (2018). Spatial scale and structural heterogeneity in skeletal muscle performance. Integrative and Comparative Biology, 58(2), 163-173. https://doi.org/10.1093/icb/icy057

Wollrab, V., Belmonte, J.M., Baldauf, L., Leptin, M., Nédeléc, F. and Koenderink, G.H. (2019). Polarity sorting drives remodeling of actin-myosin networks. Journal of Cell Science, 132(4), jcs219717. https:// doi.org/10.1242/jcs.219717

Xiong, Y.L. and Kenney, P.B. (1999). Functionality of proteins in meat products. 52nd Annual Reciprocal Meat Conference, 52, 67-69. 